\title{
POGIL in CS1: Evidence for Student Learning and Belonging
}

\author{
Chris Mayfield \\ James Madison University \\ Harrisonburg, Virginia, USA \\ mayfiecs@jmu.edu
}

\author{
Sukanya Kannan Moudgalya \\ Michigan State University \\ East Lansing, MI, USA \\ moudgal1@msu.edu
}

\author{
Aman Yadav \\ Michigan State University \\ East Lansing, MI, USA \\ ayadav@msu.edu
}

\author{
Clif Kussmaul \\ Green Mango Associates, LLC \\ Bethlehem, PA, USA \\ clif@kussmaul.org
}

\author{
Helen H. Hu \\ Westminster College \\ Salt Lake City, UT, USA \\ hhu@westminstercollege.edu
}

\begin{abstract}
For the past ten years, computer science instructors have adopted Process Oriented Guided Inquiry Learning (POGIL). Other STEM disciplines have shown conclusively that POGIL impacts student learning and knowledge retention. However, most research about POGIL in computer science has focused on perceptions and experiences, not learning outcomes. In this study, we examined the influence of POGIL on student learning in CS1. We collected data from all sections of CS1 at the same institution. Four of the faculty implemented POGIL, and three taught with other active methods. The learning data included pre and post assessments, midterm and final exams, and a retention test at the beginning of the next course. Students also completed three surveys about their prior programming experience, sense of belonging, and perceptions of teamwork. We used multiple regression to analyze the relationship between the survey data and learning outcomes. Our results show that students in the POGIL sections outperformed students in the other sections. POGIL students scored higher on the post-test, and a higher proportion of them met the grade requirement to progress to the next course. After the five-week winter break, POGIL students had higher and more consistent scores on the retention test. These results provide evidence that POGIL can be very effective as an instructional technique in computer science.
\end{abstract}

\section{CCS CONCEPTS}

- Social and professional topics $\rightarrow$ Computer science education; CS1; • Applied computing $\rightarrow$ Collaborative learning.

\section{KEYWORDS}

active learning, collaborative learning, comparative study

ACM Reference Format:

Chris Mayfield, Sukanya Kannan Moudgalya, Aman Yadav, Clif Kussmaul, and Helen H. Hu. 2022. POGIL in CS1: Evidence for Student Learning and Belonging. In Proceedings of the 53rd ACM Technical Symposium on Computer Science Education V. 1 (SIGCSE 2022), March 3-5, 2022, Providence, RI, USA. ACM, New York, NY, USA, 7 pages. https://doi.org/10.1145/3478431.3499296

Permission to make digital or hard copies of part or all of this work for personal or classroom use is granted without fee provided that copies are not made or distributed for profit or commercial advantage and that copies bear this notice and the full citation on the first page. Copyrights for third-party components of this work must be honored

For all other uses, contact the owner/author(s).

SIGCSE 2022, March 3-5, 2022, Providence, RI, USA

(c) 2022 Copyright held by the owner/author(s).

ACM ISBN 978-1-4503-9070-5/22/03.

https://doi.org/10.1145/3478431.3499296

\section{INTRODUCTION}

POGIL is a research-based instructional strategy that is becoming increasingly common in computer science. When implementing POGIL, instructors organize their classes into self-managed teams of 3-4 students [12]. The teams work through activities designed to guide them to construct their own understanding of key concepts. In addition, students practice important process skills such as communication, teamwork, critical thinking, and problem solving. The instructor (or teaching assistant) is not a lecturer or a passive observer but an active facilitator. They observe teams as they work, help address problems that arise, and lead occasional discussions among teams. Typically, teams work during scheduled class time, although POGIL can be adapted for synchronous and asynchronous online environments.

A POGIL activity generally consists of a set of models followed by questions. Each model represents a key concept and can take many forms-a graph or table of data, a diagram, source code, or a series of examples. They are accessible to students with no prior knowledge of the concepts, and they often include elements to compare or contrast. Questions in a POGIL activity follow an explore-inventapply learning cycle [8]. The first few questions prompt teams to explore the model and notice key elements or differences. Later questions prompt them to invent their own understanding of the concept, often in their own words. Final questions prompt them to apply the concept in a different context.

For example, in a POGIL activity for CS1, the model might be a short program with sample output. Explore questions might direct student attention to new syntax, important variables, or statements. Invent questions might prompt students to explain how the new syntax works or the effects of changing the order of the statements. Apply questions might prompt students to predict the output of a different program or to write a short program using the concept they just learned. Sample activities for a variety of computer science courses are available at cspogil.org. For more information about implementing POGIL, see pogil.org and a recent book [16].

POGIL has been shown to increase student outcomes in chemistry, biology, and other fields. However, little research on student learning outcomes has been conducted about POGIL in computer science. Recent work in computer science considered the impact of POGIL on student perceptions of teamwork [20] and sense of belonging [13]. However, these studies did not consider the impact of teamwork or belonging on learning outcomes. We therefore set out to answer the following research questions: 
(1) What impact does the use of POGIL have on student learning outcomes in CS1?

(2) What impact does the use of POGIL have on students' retention of CS1 knowledge?

(3) How does POGIL influence students' sense of belonging?

(4) How do perceptions of teamwork and sense of belonging influence learning outcomes?

To answer these questions, we conducted a year-long study at James Madison University (JMU), a public university in the United States. JMU is teaching-oriented and has about 20,000 undergraduate students, $650 \mathrm{CS}$ majors, and $20 \mathrm{CS}$ faculty. We chose JMU because it has many sections of CS1 taught by multiple faculty each term. In addition, one of the authors is at the university, making it easier to get IRB approval and collect reliable data. (This author did not teach CS1 during the study.) During the 2019-2020 academic year, nearly every student who took CS1 consented to participate in our study. We surveyed and assessed the students at multiple points in the semester, and we collected their exam scores.

Our study produced two main results. First, students in POGIL sections outperformed students in other sections, both during CS1 and at the beginning of the next course. Second, sense of belonging increased for students in POGIL sections and decreased for students in other sections. We analyzed relationships between prior programming experience, perceptions of teamwork, sense of belonging, and learning outcomes. Our analysis shows that teamwork and belonging had about as much influence on final exam scores as prior programming experience. This work demonstrates that POGIL can be an effective technique for students to learn CS concepts and increase their sense of belonging in CS.

\section{RELATED WORK}

Numerous studies have explored how POGIL affects student perceptions, content learning, and skill development. For example, a meta-analysis of 21 studies involving 7,876 students found that POGIL had a small effect (effect size $=0.29$ ) on achievement outcomes and substantially improved the odds of passing a course (odds ratio=2.02) [18]. A more recent literature review examined 43 studies reporting academic performance or survey results involving POGIL [11]. Our work contributes to this body of literature by establishing new results in computer science. The following paragraphs summarize research on POGIL most related to our study.

The seminal paper on POGIL and student learning was published over twenty years ago [4]. At a liberal arts college, the year-long general chemistry course was taught in sections of roughly 25 students. In fall 1994, the instructors switched from a more traditional format to POGIL. Comparing final course grades in years before (1990-1994) and after (1994-1997) the switch, the percentage of unsuccessful students (earning grades of D, W, or F) decreased from $21.9 \%$ to $9.6 \%$. In our study, we did not compare grade distributions before and after the instructors switched to POGIL, because they adopted POGIL in different years. However, we did compare success rates between the POGIL and other sections of CS1.

Our work is most similar to a study in organic chemistry at a large urban university about fifteen years ago [15]. The first semester organic chemistry course was taught in sections of roughly 100 students. In Fall 2003, one instructor switched from a traditional lecture format to POGIL. The location, time, textbook, and test formats remained the same. Class averages with POGIL (in 2003 and 2004) were around $10 \%$ higher than with lecture (in 2002), and POGIL students had higher scores on a common final exam. In Spring 2004 and 2005, the second semester organic chemistry course started with an assessment quiz on content from the first semester. Students from POGIL sections scored 25-30\% higher on the quiz, even when a non-POGIL instructor wrote the quiz. Our study replicated this latter result in computer science using an assessment quiz at the beginning of the second semester course.

Early work on POGIL in computer science included experience reports and descriptions of courses and activities (e.g., [2, 3, 10, 17]). Later studies considered student pass rates, student perceptions, and instructor perceptions. Converting a CS1 course to POGIL increased pass rates for female students but not males [7]. In a CS1 course with 29 POGIL-like activities, exam scores were significantly higher overall and by major, ethnicity, and gender, compared to a traditional course [1]. In a capstone course, POGIL activities helped students understand the importance of communication in real software projects [9]. A POGIL CS0 course increased student interest in taking more computer science courses [5]. In a survey of CS instructors using POGIL, most reported positive impacts [6].

Recent work in introductory computer science has examined faculty perceptions of implementing POGIL and its influence on student outcomes. Yadav et al. found that faculty were motivated to adopt POGIL in order to improve student learning outcomes and engagement [19]. In a later study, they examined students' perceptions of POGIL in CS1 using an adapted survey on teamwork and an accompanying learning assessment [20]. The majority of students surveyed found working in POGIL teams to be a valuable experience, and over $60 \%$ reported it helped them learn more than if they studied alone. Moudgalya et al. validated an instrument to measure sense of belonging in introductory CS courses, including many taught with POGIL [13]. We adopted the teamwork survey, learning assessment, and belonging survey from this body of work.

\section{DATA COLLECTION}

At the institution we studied, the traditional CS1 content is split across two courses, both of which are taught in Java. We will refer to the first semester course as CS1-A and the second semester course as CS1-B. Students are expected to earn a "B-" or higher grade in both courses to be admitted into the CS major.

The first ten weeks of CS1-A focus on the fundamentals of programming: variables and operators, input and output, methods, conditionals, loops, and arrays. The last five weeks of CS1-A introduce class design, unit testing, and object-oriented programming. CS1B studies more advanced topics like inheritance, polymorphism, abstract classes, interfaces, collections, and recursion.

It is important to note that all sections of these courses (not just the POGIL sections) included some aspect of active learning. The faculty used various methods, including interactive lectures, peer instruction, pair programming, and flipped classroom. POGIL instructors used these methods as well, in addition to facilitating at least one POGIL activity per week.

All students enrolled in CS1-A during the 2019-2020 academic year were invited to participate in the study. Table 1 summarizes 
the number of sections, faculty, and students. About $90 \%$ of students consented to participate, and most of them completed at least one survey and one assessment.

Table 1: Enrollment Statistics for CS1-A

\begin{tabular}{|c|c|c|c|c|c|}
\hline Term & Method & Sections & Faculty & Enroll & Consent \\
\hline Fall & POGIL & 8 & 4 & 224 & 212 \\
\hline 2019 & Other & 2 & 2 & 58 & 50 \\
\hline Spring & POGIL & 2 & 1 & 59 & 56 \\
\hline 2020 & Other & 4 & 2 & 116 & 98 \\
\hline \multicolumn{2}{|c|}{ Total (unique) } & 16 & 7 & 417 & 382 \\
\hline
\end{tabular}

Table 2 summarizes the data that we collected from students. We gave a Pre-Test and Post-Test during CS1-A, and a Ret-Test ("retention test") during the first week of CS1-B. We also surveyed students near the beginning, middle, and end of CS1-A. All surveys and assessments were given during class time as a regular part of the course. Finally, we collected the students' midterm and final exam scores from CS1-A.

Table 2: Summary of Student Data

\begin{tabular}{lll}
\hline Timing & Instrument & Details \\
\hline Week 1 & Pre-Test & 10 multiple choice from SCS1 \\
Week 2 & Survey \#1 & Experience, belonging (5 items) \\
Week 8 & Survey \#2 & Sense of belonging (30 items) \\
Week 11 & Post-Test & 10 fill in blank, based on SCS1 \\
Week 13 & Survey \#3 & Teamwork, belonging (5 items) \\
\hline CS1-B & Ret-Test & Based on CS1-A final exam \\
\hline
\end{tabular}

\subsection{Assessments}

The Pre-Test consisted of 10 multiple-choice questions from the SCS1 knowledge assessment [14]. It focused on five concepts from the first half of CS1-A (two questions each): operators, methods, decisions, loops, and arrays. Half of the questions were definitional in nature, and the other half were a mix of tracing and code completion.

Students were given 20 minutes to complete the Pre-Test during the second day of class. The Pre-Test was unannounced; instructors explained they simply wanted to find out what concepts students might already know. They also assured students that it was okay if they had no prior knowledge or experience. Each question included the multiple-choice option, "I am unfamiliar with this topic."

Instructors also explained that the test was in a "pseudocode" language because different students might have backgrounds in different languages. Therefore, the Pre-Test was designed not to favor those who had already seen Java. The Pre-Test was administered electronically using Canvas, and the questions were automatically graded. Scores ranged from 0 to 10 (with 1 point per question).

The Post-Test, which we adopted from [20], consisted of 10 fill-in-the-blank questions, most of which were based on SCS1. It focused on the same concepts as the Pre-Test, but it placed more emphasis on code tracing. We used this test to study the impact of POGIL on students' development of conceptual knowledge.

In contrast to the Pre-Test, the Post-Test questions used Java syntax. It was given the week after the second midterm exam, which assessed many of the same concepts. Instructors motivated the Post-Test as a "second chance" for students to demonstrate their knowledge about concepts they might have missed on the midterm.

Students were given 20 minutes to complete the Post-Test on paper during class time. Post-tests from all sections were collected and graded by the same researcher using Gradescope. Each question was worth three points (for a total of 30), and partial credit was given based on a rubric for each question.

The Ret-Test was designed by multiple CS1 faculty, based on the final exams from the previous semester. It was given as a surprise quiz on the second day of CS1-B for instructors to find out what knowledge students retained over the break. We used this test to study the impact of POGIL on students' retention of knowledge.

Concepts included: evaluating arithmetic and logic expressions; tracing decisions, loops, and methods; implementing sequential search using an array; writing statements that use objects, based on a UML diagram; and tracing the execution of a program that aliases objects.

Students were given 20 minutes to complete the Ret-Test at the end of class. Tests from all sections were collected and graded by the same researcher, again using Gradescope. Each question was worth 6-12 points (for a total of 40), and partial credit was given based on a rubric for each question.

\subsection{Surveys}

During the second week of class (immediately after the add/drop deadline), we visited each section of CS1-A to introduce the research project. We explained that we were interested in studying the effects of the various active learning strategies that their instructors were using. We invited students to participate in the study and consent to having their exam scores shared with the research team. To encourage participation, we announced that students who complete all three surveys would be entered into a drawing for Amazon gift cards. At least one student from each section would be selected.

After answering questions and collecting consent forms, we distributed Survey \#1. It asked questions about students' prior programming experience, how confident they were, and demographic information (age group, gender identity, and ethnicity). We administered Survey \#2 in the middle of the course, one week before the withdrawal deadline (for a "W" grade). This survey was the sense of belonging instrument from [13]. It asked 30 questions about the student's belonging in the course and in the broader computer science community. Finally, near the end of the course, we administered Survey \#3, which we adopted from [20]. This survey asked students 13 questions about two factors: learning and decision making, and collaboration and problem solving.

\section{LEARNING RESULTS}

In Fall 2019, 188 of 282 students completed all three surveys and both assessments, yielding an overall response rate of $67 \%$. Of those 188 students, 114 (61\%) enrolled in CS1-B the next semester and took 

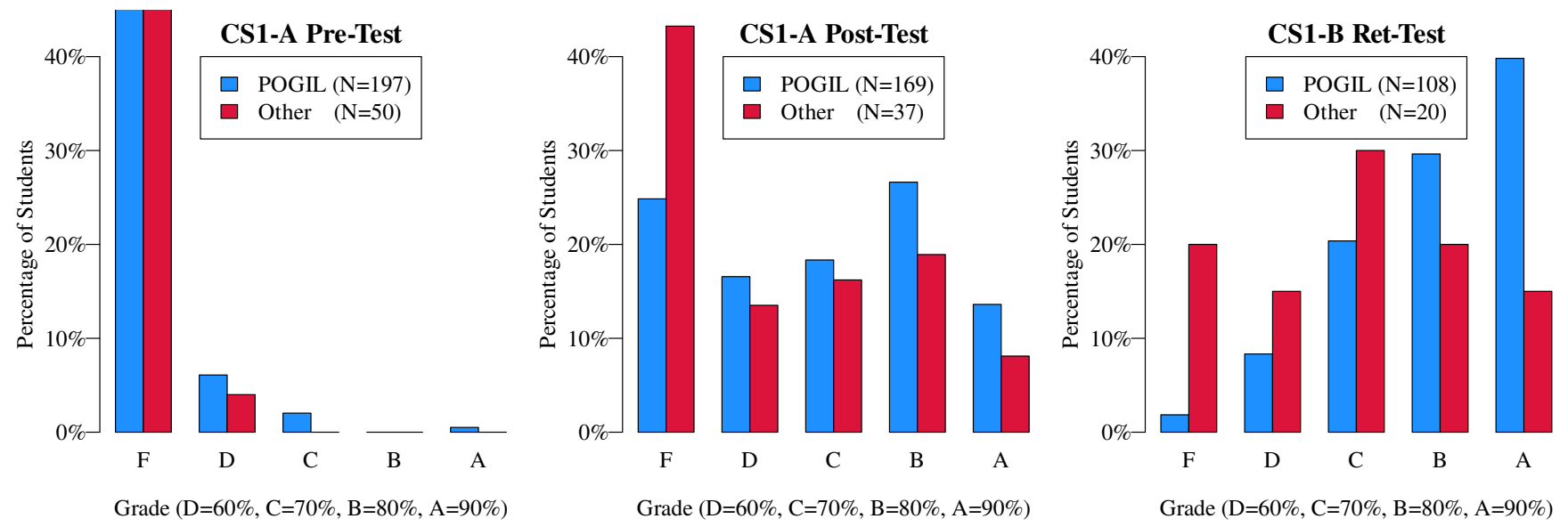

Figure 1: Grade distributions for Pre, Post, and Retention tests

the Ret-Test. In Spring 2020, however, the response rate dropped to $47 \%$ because of the COVID-19 pandemic. Therefore, most of the next two sections' results will be based only on the fall semester. The spring results were similar, but they are also less reliable, given that instruction moved online in the middle of the semester.

The six faculty teaching in the fall used the same programming assignments so that all students would have a similar experience. The midterm and final exams were not identical across sections, but the faculty worked from a common set of learning objectives. The Pre-Test, Post-Test, and Ret-Test developed for the research study were the same for all students, which gives us a common measure from which to make comparisons.

\subsection{Performance on Assessments}

Figure 1 summarizes the results of the three learning assessments. Student performance on the Pre-Test was comparable across POGIL and Other sections. The POGIL students had a slightly higher mean than the Other students ( $30 \%$ vs $25 \%$ ), but this difference is not significant $(p=0.136)$.

On the Post-Test, POGIL students had a mean of $70 \%$, and Other students had a mean of $65 \%$; this difference was also not significant ( $p=0.175)$. However, the distribution of scores was rather different. In particular, $43 \%$ of Other students failed the Post-Test, compared to $25 \%$ of POGIL students.

The results of the retention test were most compelling. POGIL students had a mean score of $84 \%$, in contrast to $73 \%$ for the Other students, which is statistically significant $(p=0.001)$. Furthermore, the distribution of scores is completely different. $40 \%$ of the POGIL students got an "A" grade on the Ret-Test compared to $15 \%$ of the Other students. $2 \%$ of the POGIL students got an "F" grade, in contrast to $20 \%$ of the Other students.

$70 \%$ of the POGIL students-versus $35 \%$ of the Other studentswere able to pass the Ret-Test with a "B-" or higher grade. All but two students who took the Ret-Test had earned a "B-" or higher grade on the CS1-A final exam. The Ret-Test was unannounced and similar in content to the CS1-A final exam, which the students had just taken five weeks before. This result suggests that POGIL students were better able to retain what they had learned in CS1-A, without having to review the material first.

\subsection{From Pre to Post to Retention}

Figure 2 includes three scatter plots that show the scores for each student. The left plot shows the relationship between Pre-Test and Post-Test scores. As expected, students who scored higher on the Pre-Test tended to score higher on the Post-Test. However, the regression line for POGIL students is slighty steeper, suggesting that POGIL students had learned a bit more during those ten weeks.

The middle plot shows the relationship between Post-Test and Retention-Test scores. POGIL students who scored higher on the Post-Test tended to score higher on the Ret-Test. However, this was not the case for the Other students; their scores tended to decrease! This result again suggests that POGIL students retained knowledge better than students from the Other sections.

The right plot compares final exam scores with Ret-Test scores. We normalized the final exam scores to account for variance across different sections. Both the POGIL students and the Other students had a similar trend: those who did better on the final exam also did better on the Ret-Test. However, the POGIL students did better overall, as shown by the regression lines.

\subsection{Progression to the Next Course}

POGIL students not only scored higher on the learning assessments; they also had higher success rates (and lower failure rates) in CS1-A. Table 3 shows the percentage of students who met the "B-" grade requirement to progress to CS1-B. It also shows the percentage of students who received a "D" or "F" grade, and the percentage of students who withdrew from the course before the 10th week.

In the fall semester, $56 \%$ of the POGIL students met the "B-" cutoff, but only $38 \%$ of the Other students did. A chi-square test indicates this difference is statistically significant $(p=.019)$. The POGIL and Other sections had comparable D/F/W rates, but the Other sections had more " $C$ " grades. The spring semester percentages are also shown, but they are less reliable because of the COVID-19 pandemic. Still, the POGIL students had a slightly higher progression 

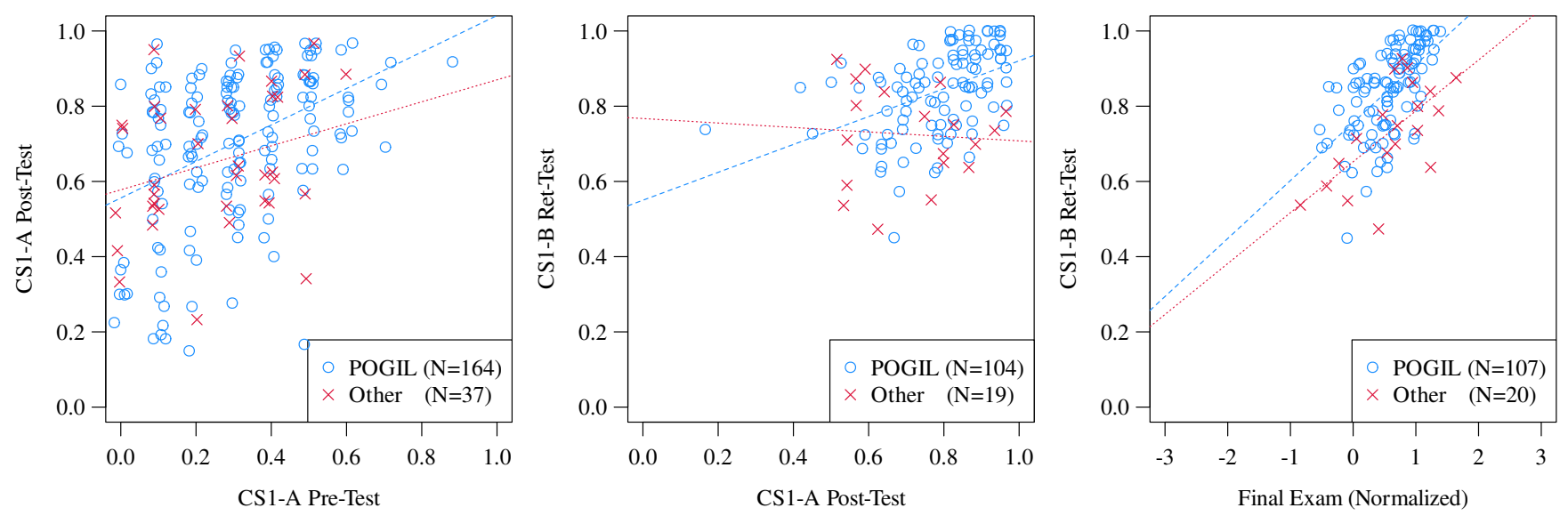

Figure 2: Comparison of test scores: Pre vs Post, Post vs Retention, and Final Exam vs Retention

rate, in spite of having a slightly higher withdrawal rate. These results are consistent with the POGIL literature [18].

Table 3: Students success rates in CS1-A

\begin{tabular}{ll|ccc}
\hline Term & Method & A/B Grade & D/F Grade & Withdrew \\
\hline Fall & POGIL & $56 \%$ & $13 \%$ & $16 \%$ \\
2019 & Other & $38 \%$ & $12 \%$ & $16 \%$ \\
\hline Spring & POGIL & $46 \%$ & $19 \%$ & $17 \%$ \\
2020 & Other & $42 \%$ & $23 \%$ & $12 \%$ \\
\hline
\end{tabular}

\section{BELONGING RESULTS}

\subsection{Change in Sense of Belonging}

We wanted to look at sense of belonging measures and see if they were higher in POGIL sections compared to Other sections. In order to study changes in sense of belonging over time, we included five belonging items on all three surveys:

- I feel that I belong to the computer science community.

- I feel accepted.

- I feel like an outsider.

- I try to say little as possible.

- I trust my instructors to be committed to helping me learn. These items turned out to be a reasonable approximation of sense of belonging, with a correlation coefficient $R^{2}=0.8131$. We selected these five items to avoid making the surveys too long. In hindsight, choosing a specific factor from the survey, such as Membership, would have served us better for internal reliability [13]. However, we still wished to explore and hypothesize how belonging changed in POGIL sections and how that, in turn, influenced test scores.

Each of the five items were rated on a scale of 1 to 5 . We computed sense of belonging scores by adding the item responses together for a 25-point scale. Figure 3 shows the distribution of belonging scores from each of the three surveys. At the beginning of the semester, POGIL and Other students had comparable inter-quartile ranges but different medians (POGIL=19, Other=20). By the middle of the semester, the medians were the same, but the range of Other scores decreased by one point. At the end of the semester, the POGIL range increased by one point, while the Other range remained the same. We admit that differences between medians are not statistically significant, as shown by overlapping notches in the box plots.

\subsection{Influence on Final Exam}

We wished to examine the reasons for the increased sense of belonging and test scores in POGIL sections compared to other sections. We hypothesized that one reason for the increase in sense of belonging could be due to the effect of teamwork, as teams were particular to the POGIL sections. We ran a linear regression analysis to examine the effects of teamwork (measured at week 13) on both their sense of belonging (from week 13) and their final exam scores (measured at week 15). We also ran a regression analysis to examine the effect of sense of belonging on test scores. In all cases, we controlled for Pre-Test scores.

Results: The whole model we tested, including the regression equations, is represented in Figure 4. It relates students' teamwork perceptions, their Pre-Test scores (i.e., prior knowledge), and their sense of belonging at week 13 , to their final exam scores.

The first regression analysis we ran was on teamwork affecting test scores separately, and teamwork affecting sense of belonging separately (i.e., simple linear regressions). We found that teamwork had no effect on exam scores, but it positively influenced students' sense of belonging. As teamwork did not influence the final exam scores directly, we did not study that relationship further. Instead, we focused on how teamwork affects sense of belonging, which in turn affects the final exam scores.

We then did a multiple regression with teamwork and Pre-Test scores on sense of belonging and found that, despite the addition of Pre-Test scores in the model, teamwork still positively affected the sense of belonging. This model had an $R^{2}=0.133$, which means that Pre-Test and teamwork, together, explain about $13 \%$ of the variance in sense of belonging. See Figure 4, model number 2, for more details on this regression.

Finally, we did a multiple regression with sense of belonging and Pre-Test scores to see their effects on the final exam scores. 

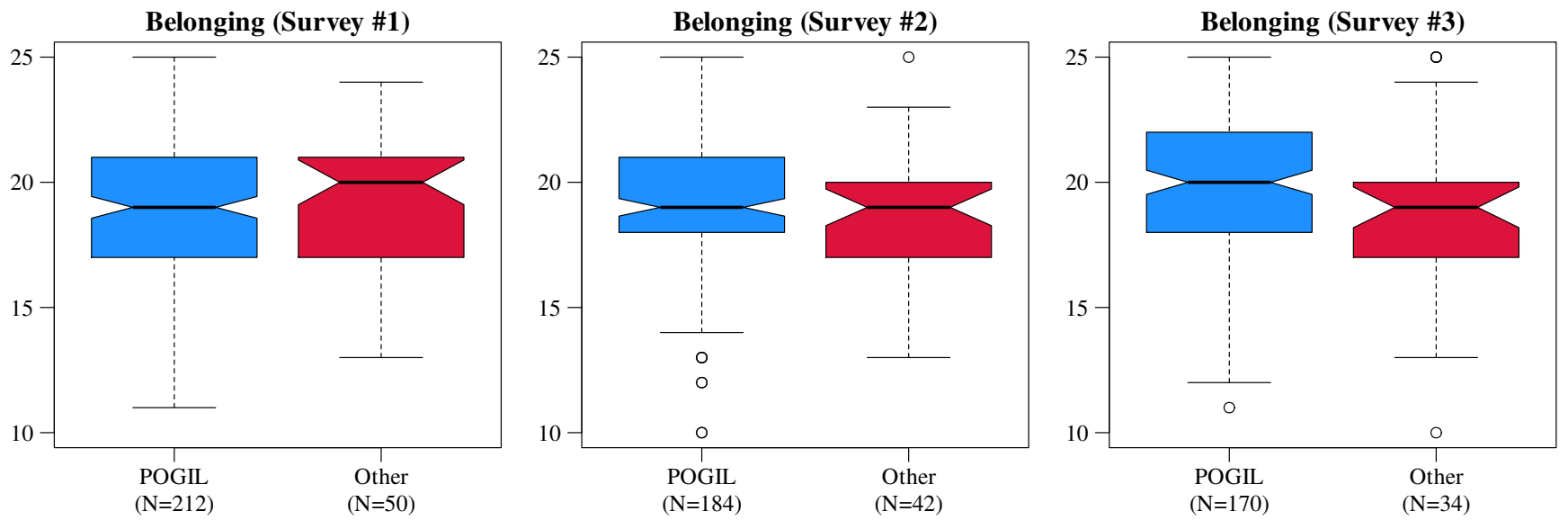

Figure 3: Sense of belonging at the beginning, middle, and end of CS1-A

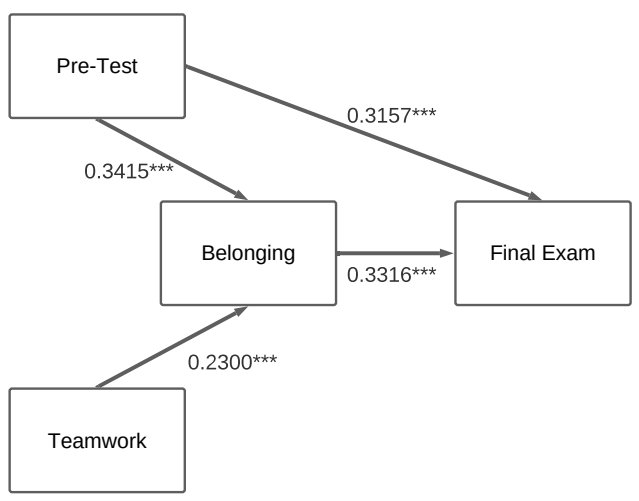

\begin{tabular}{c|c|c|c|c}
\hline \multirow{2}{*}{ Model } & \multirow{2}{*}{ Regressors } & \multicolumn{2}{|c|}{ Unstd. Coefficients } & Std. Coeffs. \\
\cline { 3 - 5 } & & $\mathrm{B}$ & Std Error & $\beta$ \\
\hline 1) Teamwork predicting & Constant & 0.4911 & 0.4065 & 0.0000 \\
Final Exam score & Teamwork & -0.1288 & 0.1030 & -0.0889 \\
\hline 2) Pre-Test and & Constant & $2.4161^{* * *}$ & 0.2805 & $0.0000^{* * *}$ \\
Teamwork predicting & Pre-Test & $0.0852^{* * *}$ & 0.0250 & $0.3415^{* * *}$ \\
Sense of Belonging & Teamwork & $0.3303^{* * *}$ & 0.0652 & $0.2300^{* * *}$ \\
\hline 3) Pre-Test and & Constant & $-2.4845^{* * *}$ & 0.3817 & $0.0000^{* * *}$ \\
Belonging predicting & Pre-Test & $0.1740^{* * *}$ & 0.0352 & $0.3157^{* * *}$ \\
Final Exam score & Belonging & $0.4980^{* * *}$ & 0.0958 & $0.3316^{* * *}$ \\
\hline
\end{tabular}

Model 1) $R^{2}=0.003$, Model 2) $R^{2}=0.133$, Model 3) $R^{2}=0.240$

Figure 4: Multiple regression model for Pre-Test, Teamwork, and Belonging predicting Final Exam scores

We found that, accounting for Pre-Test scores, students' sense of belonging positively affected their final exam scores. This model had an $R^{2}=0.240$, which means that Pre-Test and sense of belonging, together, explain $24 \%$ of the variance in the final exam. See Figure 4 , model number 3 , for more details on this regression.

Discussion: In the regression model, we found that sense of belonging positively influenced a student's final exam score, which is consistent with prior literature. Also, as mentioned in the previous section, the sense of belonging was higher for POGIL students than non-POGIL students. Sense of belonging in turn would affect test scores, which could be one reason why POGIL students had higher scores on the Post-Test during CS1-A.

In fact, sense of belonging had a positive effect on learning outcomes for all students, and a positive perception of teamwork had a positive effect on the students' sense of belonging. Given these details, we hypothesize that teamwork in POGIL sections positively influenced and increased students' sense of belonging. This increase in sense of belonging, in turn, may have contributed to the increase in learning outcomes in POGIL sections.

\section{CONCLUSION}

This paper summarizes the results of a study about POGIL in CS1. Our first question focused on student learning outcomes. We showed that POGIL students performed better on the Post-Test, and a higher percentage of them progressed to the next course. Our second question focused on the retention of knowledge. We showed that POGIL students performed better on the Retention Test, and more consistently with their Post-Test and final exam scores.

Our third question considered the influence of teamwork and belonging. We did not see major differences in teamwork perceptions, but we did notice a slight increase in belonging for POGIL students. Our fourth question explored relationships among teamwork, belonging, and learning. We developed a model, using multiple linear regression, to quantify these relationships.

In future work, we hope to further refine and validate our model. We also hope to examine gender, racial, and ethnic differences, for which our current sample size was too small to draw conclusions. Finally, we look forward to studying what aspects of POGIL help students feel a higher sense of belonging, and how that contributes to learning outcomes. 


\section{ACKNOWLEDGMENTS}

The authors thank the National Science Foundation for support under award DUE-1626765. All opinions reflected in this paper are those of the authors and not necessarily those of the National Science Foundation. Special thanks to Michael Kirkpatrick who gave feedback about the design and analysis of the research study. We also thank the faculty who participated in the study and helped us to collect data from their students.

\section{REFERENCES}

[1] Leland Beck and Alexander Chizhik. 2013. Cooperative learning instructional methods for CS1: Design, implementation, and evaluation. Transactions on Computing Education 13, 3 (2013), 10:1-10:21. https://doi.org/10.1145/2492686

[2] S. Jeff Cold. 2013. Partially Flipped: Experiences Using POGIL. In Proceedings of the 14th Annual ACM SIGITE Conference on Information Technology Education. ACM, New York, NY, USA, 133-134. https://doi.org/10.1145/2512276.2512314

[3] Andrea De Palma. 2005. Engaging students through the guided-inquiry cycle. In Proceedings of Redesigning Pedagogy: Research, Policy, Practice. National Institute of Education, Nanyang Technological University, Singapore.

[4] John J. Farrell, Richard S. Moog, and James N. Spencer. 1999. A Guided-Inquiry General Chemistry Course. Journal of Chemical Education 76, 4 (1999), 570-574.

[5] Helen Hu and Brian Avery. 2015. CS Principles with POGIL activities as a learning community. Journal of Computing Sciences in Colleges 31, 2 (2015), 79-86.

[6] Helen H. Hu, Clifton Kussmaul, Brian Knaeble, Chris Mayfield, and Aman Yadav. 2016. Results from a survey on faculty adoption of Process Oriented Guided Inquiry Learning (POGIL) in Computer Science. In Proc. of the Conf. on Innov. and Tech. in CS Edu. (ITiCSE). ACM, 186-191.

[7] Helen H. Hu and Tricia D. Shepherd. 2013. Using POGIL to Help Students Learn to Program. Trans. on Comp. Edu. (ToCE) 13, 3, Article 13 (Aug. 2013), 23 pages.

[8] R. Karplus and Herbert D. Thier. 1967. A New Look at Elementary School Science; Science Curriculum Improvement Study. Rand McNally \& Co.

[9] Shreya Kumar and Charles Wallace. 2014. Instruction in software project communication through guided inquiry and reflection. In Proceedings of the Frontiers in Education (FIE) Conference. Madrid, Spain.

[10] Clifton Kussmaul. 2011. Process Oriented Guided Inquiry Learning for Soft Computing. In Advances in Computing and Communications, Ajith Abraham, Jaime Lloret Mauri, John F. Buford, Junichi Suzuki, and Sabu M. Thampi (Eds.).
Springer, Berlin, Heidelberg, 533-542. https://doi.org/10.1007/978-3-642-227202_56

[11] Stanley M. Lo and Jonathan I. Mendez. 2019. L: Learning - The Evidence. Stylus Publishing, LLC, 85-110.

[12] Richard S. Moog. 2014. Process Oriented Guided Inquiry Learning. In Integrating Cognitive Science with Innovative Teaching in STEM Disciplines, Mark A. McDaniel, Regina F. Frey, Susan M. Fitzpatrick, and Henry L. Roediger III (Eds.). Washington University, Saint Louis, MO, USA, Chapter 8, 147-166.

[13] Sukanya Kannan Moudgalya, Chris Mayfield, Aman Yadav, Helen H. Hu, and Clif Kussmaul. 2021. Measuring Students' Sense of Belonging in Introductory CS Courses. In Proceedings of the 52nd ACM Technical Symposium on Computer Science Education. Association for Computing Machinery, New York, NY, USA, 445-451. https://doi.org/10.1145/3408877.3432425

[14] Miranda C. Parker, Mark Guzdial, and Shelly Engleman. 2016. Replication, Validation, and Use of a Language Independent CS1 Knowledge Assessment. In ACM Conference on International Computing Education Research. Association for Computing Machinery, New York, NY, USA, 93-101.

[15] Suzanne M. Ruder and Sally S. Hunnicutt. 2008. POGIL in Chemistry Courses at a Large Urban University: A Case Study. American Chemical Society, Washington, DC, Chapter 12, 133-147.

[16] Shawn R. Simonson (Ed.). 2019. POGIL: An Introduction to Process Oriented Guided Inquiry Learning for Those Who Wish to Empower Learners. Stylus Publishing, LLC, Sterling, Virginia. Google-Books-ID: NL2SDwAAQBAJ

[17] Tammy VanDeGrift. 2017. POGIL activities in data structures: What do students value?. In Proceedings of the ACM SIGCSE Technical Symposium on Computer Science Education. ACM, New York, NY, USA, 597-602. https://doi.org/10.1145/ 3017680.3017697

[18] Lindsey Walker and Abdi-Rizak M. Warfa. 2017. Process Oriented Guided Inquiry Learning (POGIL) Marginally Effects Student Achievement Measures but Substantially Increases the Odds of Passing a Course. PLOS ONE 12, 10 (2017), $1-17$.

[19] Aman Yadav, Clif Kussmaul, Chris Mayfield, and Helen H. Hu. 2019. POGIL in Computer Science: Faculty Motivation and Challenges. In Proceedings of the 50th ACM Technical Symposium on Computer Science Education (Minneapolis, MN, USA) (SIGCSE '19). Association for Computing Machinery, New York, NY, USA, 280-285. https://doi.org/10.1145/3287324.3287360

[20] Aman Yadav, Chris Mayfield, Sukanya Kannan Moudgalya, Clif Kussmaul, and Helen H. Hu. 2021. Collaborative Learning, Self-Efficacy, and Student Performance in CS1 POGIL. In Proceedings of the 52nd ACM Technical Symposium on Computer Science Education. Association for Computing Machinery, New York, NY, USA, 775-781. https://doi.org/10.1145/3408877.3432373 